\title{
PENGEMBANGAN BAHAN AJAR TEMATIK BERBASIS MODEL DISCOVERY LEARNING SISWA KELAS V DI GUGUS V KECAMATAN KERAMBITAN KABUPATEN TABANAN
}

\author{
D.G.T. Wiryani ${ }^{1}$, I.W. Lasmawan ${ }^{2}$, I.B. Putrayasa ${ }^{3}$ \\ ${ }^{123}$ Program Studi Pendidikan Dasar \\ Universitas Pendidikan Ganesha \\ Singaraja, Indonesia
}

e-mail: $\underline{\text { d.twelvawiryani@gmail.com }}{ }^{1}$, lastmaone@gmail.com ${ }^{2}$, ibputra@gmail.com $^{3}$

\begin{abstract}
Abstrak
Penelitian ini bertujuan untuk menghasilkan bahan ajar berupa buku ajar berbasis Discovery Learning pada tema I Organ Gerak Hewan dan Manusia Subtema I Organ Gerak Hewan. Penelitian ini termasuk jenis penelitian pengembangan yang menggunakan model 4D.Subjek uji coba dalam penelitian ini adalah subjek ahli yaitu ahli media, ahli materi, dan guru digugus $V$ Kecamatan Kerambitan, Kabupaten Tabanan serta siswa kelas $\mathrm{V}$ yang berjumlah 42 siswa. Teknik pengumpulan data dilakukan dengan angket. Angket digunakan untuk menilai buku ajar yang dikembangkan dari segi isi materi maupun tampilan buku ajar. Data dianalisis secara deskripsip kuantitatif dan kualitatif. Hasil penelitian ini dilihat dari kevalidan adalah sangat layak dengan nilai rata-rata 4,25, dilihat dari kepraktisan adalah sangat praktis dengan nilai rata-rata guru 89 dan nilai rata-rata siswa 82,75 dan dilihat dari efektifitas maka berada pada tingkat efektifitas sedang dengan nilai rata-rata 0,60.
\end{abstract}

Kata Kunci : Bahan Ajar; Discovery Learning; Tematik

\section{Abstract}

This study aims to produce teaching materials in the form of teaching books based on Discovery Learning on the theme I Animal and Human Organ Movements, Sub-Theme I Animal Movement Organs. This research is a type of development research using the $4 D$ model. The trial subjects in this study were expert subjects, namely media experts, material experts, and teachers in Cluster V, Kerambitan District, Tabanan Regency, as well as 42 students in grade V. The data collection technique was done by using a questionnaire. This questionnaire is used to assess textbooks developed in terms of material content and textbook appearance. Data were analyzed by descriptive quantitative and qualitative. The results of this study are seen from the validity is very feasible with an average value of 4.25 , seen from the practicality is very practical with an average score of 89 teachers and an average value of students 82.75 and seen from the effectiveness, it is at a moderate level of effectiveness. with an average value of 0.60 .

Keywords : Teaching Materials; Discovery Learning; Thematic

\section{PENDAHULUAN}

Di abad 21 ilmu pengetahuan serta teknologi sangat berkembang pesat di abad 21. Agar bisa bersaing di era milenial ini diharapakan adanya sumber daya manusia yang produktif dan terampil. Proses untuk mengubah tingkah laku seseorang pada usaha memanusiakan manusia melalui suatu upaya pelatihan dan pengajaran diartikan sebagai pendidikan. Tujuan pendidikan adalah mengembangkan

kepribadian, kemampuan ketika bekerja, serta mampu menguasai pengetahuan. Cara menggapai tujuan pendidikan diperlukan pengembangan kemampuan yang ada melalui implementasi berbagai metode dan alat.

Pelaksanaan pendidikan di Negara Indonesia dengan menggunakan sistem kurikulum. Program kurikulum 2013 telah dirancang oleh Pemerintah Indonesia 
merupakan pengembangan dari Kurikulum Tingkat Satuan Pendidikan (KTSP). Cakupan kurikulum 2013 yakni keterampilan, sikap, serta pengetahuan. Karakteristik dari kurikulum 2013 yaitu bersifat tematik.

Trianto (2011:152) menetapkan bahwa pembelajaran tematik menawarkan pembelajaran yang membuat kegiatan belajar yang relevan serta bermakna bagi peserta didik melalui pemberdayaan pengalaman dan pengetahuan peserta didik untuk membantu memahami dunia. Trianto (2011:154) mengutarakan pembelajaran tematik diartikan dengan "model pembelajaran yang menggabungkan beberapa bahan pembelajaran dari berbagai standar kompetensi utama dari satu topik atau lebih". Pembelajaran tematik sering dikenal sebagai pembelajaran tematik terintegritas. Pembelajaran tematik berawal dari dikembangkan untuk anak yang bertalenta serta berbakat (talented and gifted). Tetapi sekarang pembelajaran tematik harus dimiliki oleh semua siswa. Pada dasarnya, pembelajaran tematik dikembangkan guna menciptakan proses pembelajaran yang aktif secara mental dalam mengkontruksi pengetahuan berdasarkan struktur kognitif yang dimiliki setiap siswa.

Bahan ajar adalah komponen yang memiliki pengaruh terhadap kegiatan proses pembelajaran. Menurut Daryanto, dkk (2014:171) "Sekumpulan materi baik ditulis maupun tidak tersusun secara sistematis yang memberikan kesempatan peserta didik untuk belajar merupakan definisi dari bahan ajar".

Pembelajaran model discovery learning adalah model pembelajaran yang di kembangkan oleh J. Bruner berdasar pada pemahaman kognitif mengenai proses pembelajaran serta menerapkan prinsip konstruktivis (Depdiknas,2005). Model pembelajaran penemuan adalah model pembelajaran yang mengikutsertakan peserta didik guna mengorganisasikan sendiri bahan materi proses pembelajaran serta menekankan pada penemuan prinsip atau konsep yang belum di ketahui peserta didik (Kemdikbud 2016:60). Pembelajaran penemuan merupakan model pembelajaran yang memiliki kecendrungan untuk meminta peserta didik untuk melaksanakan tindakan ilmiah, eksperimen, serta observasi (Saifuddin:2014). Menurut Bruner (Wicaksono, dkk 2015:190) Pembelajaran penemuan memiliki manfaat untuk (1) meningkatkan pengetahuan peserta didik (2) proses perpindahan dalam memberikan reward ekstrinsic ke intrinsic (3) pembelajaran secara menyeluruh dapat dilalui dari proses penemua (4) instrumen dalam melatih ingatan. Discovery learning adalah model pembelajaran berlandaskan teori belajar, konstruktivis, dan penemuan. Menurut (Anitah, 2009) belajar penemuan diartikan sebagai pembelajaran yang mengikutsertakan peserta didik guna memecahkan masalah untuk mengembangkan keterampilan dan pengetahuan. Belajar secara intens dengan penemuan peserta didik mengikuti metode observasi ilmiah dengan pengawasan guru. Carin (dalam Suastra, 2017:69) proses mental individu dalam mengasimilasi konsep serta prinsip disebut discovery. Siswa akan melibatkan penggunaan proses mental guna menemukan berbagai prinsip dan konsep jika siswa melakukan (Suastra, 2017:70). Jadi model discovery learning diartikan sebagai suatu model pembelajaran yang memberikan kesempatan siswa guna menemukan sendiri prinsip/konsep melalui penemuan-penemuan yang dilakukannnya.

Pelaksanaan pembelajaran tematik secara umum masih belum optimal. Hernawan (2009); Machali (2004) pada proses pembelajaran didominasi oleh guru. Hal ini mengindikasikan proses pembelajaran yang telah dilaksanakan tidak optimal serta masih adanya guru menerapkan model pembelajaran konvensional (Desyandri, 2012). Penelitian yang sama dilakukan oleh Desyandri; Vernanda (2017) kurang adanya kesempatan peserta didik untuk mengeksplore dirinya sendiri untuk bertanya, mengamati, mencoba, mengomunikasikan serta mengolah informasi. Siswa kurang aktif dikarenakan pembelajaran masih didominasi oleh guru. 
Hal tersebut tidak senada dengan peran guru pada abad 21, yakni: "Guru memegang peran penting dalam membantu siswa dalam mengembangkan keterampilan abad 21 dengan menerapkan metode yang meningkatkan kemampuan siswa" (Alismail \& McGuire, 2015). Cheng (2018); Malsbary (2018); Teplykh et al (2019) berpendapat peningkatan semangat siswa dalam pembelajaran dipengaruhi oleh guru, guru dituntut bekreasi serta inovatif dalam menyiapkan strategi pembelajaran dengan bantuan teknologi.

Sejauh ini prinsis-prinsip dalam mengembangkan bahan ajar belum terpenuhi hal ini terlihat dari pemberian motivasi kepada siswa masih kurang dilakukan oleh guru dalam proses pembelajaran. Daryanto dan Dwicahyono (2014) berpendapat dalam memahami yang sulit bahan ajar menyiapkan sesuatu hal yang mudah dipahami peserta didik, memotivasi siswa untuk belajar sehingga mencapai keberhasilan dalam belajar, serta memahami yang abstrak bahan ajar memberikan sesuatu yang konkret merupakan prinsip dari pengembangan bahan ajar. Kurangnya kecukupan materi dari Bahan ajar guru dalam melakukan serta memahami kompetensi dasar, serta guru belum mampu menumbuhkan rasa ingin tahu serta keaktifan siswa karena bahan ajar yang digunakan belum merangsang siswa. Hal tersebut mengartikan prinsip pengembangan bahan ajar belum terpenuhi dalam pembelajaran. Kurniasih dan Sani (2014) menyatakan dalam melakukan dan memahami kompetensi dasar diperlukan bahan ajar yang mempunyai kepadanan materi ajar serta penggunaan gambar, kutipan serta perkataan yang mampu merangsang keaktifan serta rasa ingin tahu siswa merupakan prinsip pengembangan bahan ajar.

Perlu adanya pengembangan buku ajar yang efektif dan praktis serta menggunakan model yang inovatif dalam mengatasi masalah diatas. Salah satu solusinya yakni mengembangkan buku ajar berbasis model Discovery Learning. Model pembelajaran menemukan dan mencari sendiri, serta memberikan peluang siswa memecahkan dan menemukan cara pemecahannya diartikan sebagai model discovery learning (Riyanto, 2010). Faisal (2014) berpendapat bahwa proses pembelajaran yang tidak menyediakan bentuk finalnya kepada siswa namun siswalah sendiri mengorganisasikan hal tersebut disebut pembelajaran penemuan. Amiyani dan Widjajanti (2019); Syarafina dan Mahmudi (2019); serta Capuano dan Toti (2019) proses yang tidak menyediakan bentuk final, tetapi perlu mengorganisasikan sendiri itu diartikan sebagai discovery learning.

Pada penelitian ini peneliti ingin mengetahui : (1) Bagaimana validitas (kelayakan) pengembangan bahan ajar tematik kelas V SD dengan Tema 1 Organ gerak hewan dan manusia Sub tema 1 organ gerak hewan? (2) Bagaimana kepraktisan buku ajar kelas V SD dengan Tema 1 Organ gerak hewan dan manusia Sub tema 1 organ gerak hewan? (3). Bagaimana efektivitas Bahan Ajar Tematik kelas V SD dengan Tema 1 Organ gerak hewan dan manusia Sub tema 1 organ gerak hewan?

\section{METODE}

\begin{tabular}{lrr}
\multicolumn{1}{c}{ Penelitian } & yang & dilaksanakan \\
termasuk & dalam & penelitian \\
pengembangan. & Penelitian \\
pengembangan & adalah penyederhanaan
\end{tabular} istilah dari R\&D (Research and Development). Penelitian pengembangan yang dilaksanakan memiliki tujuan guna menghasilkan produk yang efektif, senada dengan pendapat Gay (dalam Emzir, 2011:263) mengembangkan produk yang bisa digunakan di sekolah bukan untuk menguji atau merumuskan teori adalah tujuan penelitian pengembangan

Siswa kelas $\mathrm{V}$ di gugus $\mathrm{V}$ Kecamatan Kerambitan Tabanan menjadi subjek uji coba. Tahapan pengembangan diawali dengan studi pendahuluan guna mengumpulkan serta mencari informasi. Selanjutnya dilakukan desain model pengembangan. Model 4D dari Thagarajan (1974) yang menjadi dasar pengembangan ini. Empat tahapan yang perlu dilakukan pada penelitian Thagarajan yaitu pendefinisian, 
perancangan, perngembangan, serta penyebaran. Keterbatasan peneliti dari segi biaya, waktu dan tenaga dalam pengembangan ini tahapan dilakukan hingga develop tidak sampai pada tahap disseminate.

Buku ajar yang disusun peneliti diujicobakan di SD gugus V Kerambitan, Tabanan untuk kelas V. Bahan ajar ini diuji cobakan sampai tahap uji validitas, uji partikalitas, serta efektivitas.

\section{HASIL DAN PEMBAHASAN}

Validator dalam pengembangan bahan ajar ini terdiri dari 2 ahli. Hasil dari validasi bahan ajar dapat dikatakan sangat valid dengan rata-rata 4,25. Buku ajar yang telah disusun berdasarkan hasil uji validitas, selanjutnya dilakukan uji coba untuk melihat praktikalitas bahan ajar. Sebanyak 42 siswa kelas V Kecamatan Kerambitan ikut menjadi subjek dalam uji coba yang dilaksanakan pada tanggal 12 sampai dengan 16 Januari 2021. Hasil praktikalitas dilihat dari analisis angket guru dan siswa. Hasil angket didapatkan persentase $89 \%$ dan $82,75 \%$ hal ini menandakan buku ajar sangat praktis. Efektivitas buku ajar dilihat dari hasil pretest dan postest dengan nilai 0,60 kategori efektivitas sedang.

Model pengembangan pada penelitian ini berdasarkan pada Thagarajan (1974). Empat tahapan yang perlu dilakukan pada penelitian Thagarajan yaitu pendefinisian, perancangan, perngembangan, serta penyebaran. Sebanyak 42 siswa kelas V Kerambitan, Tabanan dijadikan subjek penelitian, hasil mengenai validitas serta praktikalitas diuraikan lebih lanjut.

\section{Hasil validasi buku ajar}

Bahan ajar harus divalidasi sebelum bahan ajar tersebut diujicobakan. Senada dengan argumentasi Emzir (2011:273) bahan ajar harus divalidasi sebelum diuji coba. Serta suatu bahan ajar dapat dinyatakan valid jika sudah memenuhi kriteria yang ditetapkan. Plom (2007:121) berpendapat bahwa bahan ajar dikatakan valid apabila memiliki karateristik state-ofart-knowledge. Tes yang disusun dapat dinyatakan valid apabila tes mampu mengukur yang hendak diukur (Scarvian \& Anderson dalam Suharsini, 2009). Hal tersebut disebut dengan validasi isi. Validasi konstruk merupakan komponen produk harus konsisten satu sama lain. Produk dikata valid harus memenuhi validasi isi dan konstruk. Hasil dari analisis validator bahan ajar dikembangkan dinyatakan valid

\section{Hasil uji praktikalitas buku ajar}

Buku ajar yang disusun dapat memberi kemudahan untuk guru dalam proses pembelajaran serta mudah untuk dipahami siswa mengindikasikan bahwa buku ajar yang dikembangkan dikatakan praktis. Sejalan dengan pendapat Suharsimi (2009:62) bahwa guru serta siswa dengan sangat mudah menggunakan bahan ajar karena bahan ajar mudah untuk dilaksanakan, mudah untuk diperiksa, serta dilengkapi dengan pedoman-pedoman yang jelas sering disebut praktikalitas bersifat praktis.". Bahan ajar diujicobakan kepada guru dan siswa kelas V Kecamatan Kerambitan, Kabupaten Tabanan. untuk mengetahui kepraktisan dari bahan ajar yang disusun.

\section{Hasil analisis data respon guru terhadap buku ajar}

Hasil pratikalitas bahan ajar diperoleh dari hasil angket respon siswa dan guru. Hasil partikalitas dilihat dari respon guru memberikan persentase kepraktisan sebesar $89 \%$ dapat dikategorikan sangat praktis. Hasil praktikalitas bahan ajar dari hasil respon siswa memberikan persentase sebesar $82,75 \%$, hasil tersebut mengindikasikan bahan ajar yang disusun sangat praktis.

Empat tahapan yang dilakukan untuk mengetahui keefektifan penilaian produk pengembangan bahan ajar yaitu pada tahap pertama siswa kelas $\mathrm{V}$ SD Negeri 2 Kelating. Tahap kedua siswa kelas $V$ di SD Negeri 1 Kelating, tahap ketiga siswa kelas $\mathrm{V}$ di SD Negeri 2 Penarukan. Dan tahap keempat siswa kelas V di SD Negeri 3 Penarukan.

Teknik skor rata-rata penilaian pada setiap item penelitian digunakan untuk 
menganalisis data yang didapatkan. Adapun angket siswa kelas V di Gugus V Kecamatan Kerambitan, Kabupaten Tabanan.

Hasil pre-test dan post test pada hasil belajar siswa mengindikasikan tingkat keefektifan siswa. Perhitungan NGain dapat digunakan untuk mengetahui peningkatan nilai pre test dan post test. Hasil pretest dan post tes terhadap efektifitas buku ajar memperoleh persentase tingkat efektifitas sedang dengan nilai 0,60 .

\section{PENUTUP}

Uji validitas yang melibatkan 2 orang ahli memperoleh hasil analisis dengan rata-rata 4,25. Dengan demikian buku ajar berbasis Discovery learning termasuk pada kategori "sangat valid". Kepraktisan buku ajar berbasis Discovery learning yang diukur dengan angket respon guru \& angket respon siswa diperoleh rata-rata 89 dan 82,8 dengan kategori "sangat praktis". Keefektifan buku ajar berbasis Discovery learning yang diukur dengan pre-test dan post-test diperoleh rata-rata 0,60 dengan kategori "efektifitas sedang".

Saran yang hendak diberikan untuk meningkatkan kualitas pembelajaran dalam menerapkan kurikulum 2013 pada anak Sekolah Dasar sebagai berikut :

1. Bagi pendidik disarankan mampu meningkatkan serta memunculkan ideide kreatifnya khususnya dalam pembuatan buku ajar sebagai buku pendamping kurikulum 2013.

2. Bagi siswa disarankan agar lebih antusias dan meningkatkan rasa ingin tahu dalam mengikuti pelajaran untuk meningkatkan motivasi belajar yang akan membantu siswa dalam pengembangan hasil belajar.

3. Bagi peneliti selanjutnya agar melaksanakan penelitian yang serupa untuk mendapatkan hasil yang lebih optimal dalam upaya mengembangkan bahan ajar berbasis Discovery Learning pada setiap kelas di Sekolah Dasar.

\section{DAFTAR RUJUKAN}

Alismail, H. A., \& McGuire, P. (2015). 21

St Century Standards and Curriculum: Current Research and Practice. Journal of Education and Practice, 6(6), 150-155.

Amiyani, R., \& Widjajanti, J. B. (2019). Self-confidence and mathematics achievement using guided discovery learning in scientific approach. In Journal of Physics: Conference Series (Vol. https://doi.org/10.1088/17426596/1157/4/042093

Cheng, S.-F. (2018). Application of Creative Teaching. Hu Li Za Zhi The Journal of Nursing, 65(6), 4. https://doi.org/10.6224/JN.201812_6 5(6). 01

Daryanto, \&Dwicahyono, A. (2014). Pengembangan Perangkat Pembelajaran (Silabus, RPP, PHB, Bahan Ajar). Yogyakarta: Gaya Media.

Depdiknas. (2008). Kamus Besar Bahasa Indonesia Pusat Bahasa. Jakarta: PT Gramedia.

Desyandri. (2012). The Usage of CTL Approach to Improve the Process and Learning of Singing to Studen Class III Elementary School. Jurnal Pedagogi FIP UNP.

Desyandri; Vernanda, D. (2017). Pengembangan bahan ajar tematik terpadu di kelas $v$ sekolah dasar menggunakan identifikasi masalah Desyandri. In Seminar Nasional HDPGSDI Wilayah 4 (pp. 163-174).

Faisal. (2014). Sukses Mengawali Kurikulum 2013 di SD. Yogyakarta: Diandra Creative.

Kemendikbud. (2017). Materi Pelatihan Guru Implementasi Kurikulum 2013 SD Kelas IV. Jakarta: Kemendikbud.

Kurniasih, I dan Sani, B. (2014). Implementasi Kurikulum 2013 Konsep dan Penerapan. Surabaya: Kata Pena. 
Plom, T. Dan Nieveen, N. (Eds). (2017). An Introduction to Educational Design Research. Enschede: SLO (Netherlands institute for curriculum development).

Riyanto,Y. (2010). Paradigma Baru Pembelajaran: Sebagai Referensi Bagi Pendidik dalam Implementasi Pembelajaran yang Efektif dan Berkualitas. Surabaya: Prenada Media.

Suastra, I Wayan. 2017. Pembelajaran Sains Terkini. Singaraja: Undiksha

Trianto. (2011). Pengantar Penelitian Pendidikan Bagi Pengembangan Profesi Pendidikan dan Tenaga Kependidikan. Jakarta: Prenada Media Group. 